\title{
TRADUÇÃO COMENTADA DO POEMA EM LÍNGUA BRASILEIRA DE SINAIS "VOO SOBRE RIO"
}

\author{
AN ANNOTATED TRANSLATION OF THE POEM IN BRAZILIAN SIGN \\ LANGUAGE "VOO SOBRE RIO"
}

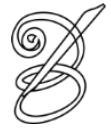 \\ Marilyn Mafra Klamt ${ }^{1}$ \\ Doutoranda em Linguística \\ (Programa de Pós-Graduação em Linguística/ UFSC/ Florianópolis/ SC/ Brasil) \\ marilynfloripa@gmail.com
}

Resumo: O presente trabalho aborda as estratégias adotadas na tradução do poema em Língua Brasileira de Sinais "Voo sobre Rio", da poetisa Fernanda Machado - registrado em vídeo e analisado a partir do software linguístico Elan - para a Língua Portuguesa. Para isto, lança mão de discussões sobre a traduzibilidade de poesia, os mitos da tradução, domesticação x estrangeirização, basendo-se principalmente nos trabalhos de Weininger (2012), Laranjeira (2003) e Venuti (1998).

Palavras-chave: tradução; poesia; língua brasileira de sinais.

Abstract: This work addresses the strategies utilized in translating Fernanda Machado's poem "Voo sobre Rio", from Brazilian Sign Language to the Portuguese language, as it was registered in video and analyzed using the linguistic software Elan. To accomplish this I make use of discussions regarding the translatability of poems, the myths of translation, domestication vs. foreignization, basing myself mainly on the works of Weininger (2012), Laranjeira (2003), and Venuti (1998).

Keywords: translation; poetry; Brazilian Sign Language.

\section{Introdução}

poesia em língua de sinais, manifestação artística da cultura surda, insere-se no 1 folclore surdo, um conjunto de histórias, piadas, poemas, narrativas de experiência 1 pessoal, fábulas que são transmitidas no seio da comunidade surda, como forma de preservação de sua identidade (CARMEL, 1996 apud SUTTON-SPENCE, 2007). A identidade surda diferencia-se da identidade ouvinte pela potência de experiências visuais vivenciadas pelos surdos e o uso das línguas de sinais, línguas minoritárias que convivem com as línguas oficiais e majoritárias dos países em que os surdos vivem. No caso do Brasil, a Língua Brasileira de Sinais, língua reconhecida legalmente como a língua das pessoas surdas do Brasil, convive com a língua oficial do país, a Língua Portuguesa. Além disto, a poesia em 
língua de sinais é uma arte em sinais (KLIMA; BELLUGI, 1979), ou seja, forma criativa de expressão que se difere da sinalização cotidiana, sinais utilizados com fim estético.

O poema analisado e traduzido neste trabalho não foi publicado, ele faz parte do acervo pessoal da poetisa Fernanda Machado - representante da geração atual de poetas surdos brasileiros - registrado em vídeo, com duração total de 3m44s. Este poema, como será demonstrado, possui estrutura rítmica bem marcada, presença de rimas e de outros elementos próprios da poesia sinalizada que devem ser levados em conta na tradução.

Desta forma, serão apresentadas algumas teorias que prometem lançar luz a questões como intraduzibilidade de poesia, mitos do ato tradutório, estrangeirização ou domesticação como processos de escolha do tradutor, em conjunto com a proposta de tradução.

Enfatiza-se, ainda, que apesar de haver diversas traduções literárias da Língua Portuguesa para a Língua Brasileira de Sinais, o contrário não é comum, ou seja, este trabalho pretende dar visibilidade à produção poética em Língua Brasileira de Sinais, que ainda permanece desconhecida da maioria das pessoas, já que é uma língua acessada por poucos ouvintes que se dedicam a estudar e compreender a cultura surda.

\section{Sobre a tradução de poesia}

Quando se fala em tradução de poesia, é comum abordar sua intraduzibilidade, ou afirmar que a poesia reside no intraduzível. Para Jakobson, por exemplo, a poesia é, por definição, intraduzível, afirmando que "somente a 'transposição criativa' é possível de uma para outra forma poética no interior da mesma língua, de uma língua para outra ou entre meios e códigos expressivos bastante diferentes" (STEINER, 2005, p. 283)

Isto porque a poesia, como nível máximo de excelência no trabalho com a linguagem, exige do tradutor, por sua vez, além de atentar para escolhas tradutórias referentes às línguas fonte e alvo, preocupar-se com a forma, ou seja, para aspectos estéticos, típicos do ofício poético. Na poesia, “[...] a língua, o código, deixa de ser apenas um suporte, um veículo, para fazer parte integrante da própria mensagem. O significante ganha terreno sobre o significado, prepondera sobre ele, gera-o" (LARANJEIRA, 2003, p. 21).

Já em 1813, Schleiermacher apontava para a dificuldade de se traduzir poesia, cujo ritmo se perde algumas vezes na tradução. É de

superior importância o elemento musical da língua que se manifesta no ritmo e na entonação. Todo o mundo nota que no espírito mais fino, o encanto supremo da arte 
em suas obras mais acabadas, se perde se aquele elemento musical é descuidado ou destruído. (SCHLEIERMACHER, 1813 apud HEIDERMANN, 2010, p. 67)

Para Laranjeira (2003), em seu "Poética da Tradução", a preocupação com a estrutura linguística e literária do original não deve fazer com que o tradutor se sinta preso à forma, a ponto de que não possa traduzir. $\mathrm{O}$ autor acredita na traduzibilidade da poesia.

\begin{abstract}
Não se pode exigir do tradutor que mantenha absolutamente tudo aquilo que uma análise linguística do original revela como pertinente à poeticidade do texto. Cabelhe, entretanto, expandir ao máximo o limite das fidelidades e, pela inventividade de seu gênio, recuperar e compensar possíveis perdas de trajeto nos diversos níveis (LARANJEIRA, 2003, p. 129)
\end{abstract}

Outra questão que se coloca é se o tradutor de poesia não deveria ser ele também poeta, já que para este ofício são exigidas outras habilidades que vão além da tradutória. Assim, no prefácio às Cartas de Ovídio (1680), Dryden afirma que "para traduzir poesia, o tradutor tem de ser poeta, deve dominar as duas línguas e entender quer as características quer o 'espírito' do autor original, além de se ajustar aos cânones estéticos da sua época". (BASSNETT, 2003, p. 105). No entanto, esta opinião não é corroborada por todos os autores.

Sobre a (in) traduzibilidade de poesia, Weininger (2012) afirma que quanto mais o tradutor adere aos mitos de equivalência, mais intraduzível será a poesia. Os cinco mitos são: mito do autor genial, mito da intenção do autor, mito do significado do texto original, mito do tradutor e mito da tradução correta. O princípio da equivalência é, para Weininger, ao mesmo tempo inevitável e perigoso nos Estudos da Tradução. Na tradução do texto poético, a equivalência se torna "inexorável e inalcançável, desejo mais árduo, tormenta e frustração extremada, igualando o tradutor ao próprio poeta, em certo sentido" (WEININGER, 2012, p. 194), pois o gênero impõe diversas exigências estéticas, como rima, métrica, ritmo, versificação etc.

Sintetizando as ideias de Weininger, os mitos não se sustentam, pois: os textos não são construídos do vazio, todo texto é fruto de intertextualidade (mito do autor genial); é impossível saber as intenções do autor quando escreveu um texto, nem mesmo quando o autor fala sobre elas (mito da intenção do autor); é difícil, se não impossível saber o significado do texto, já que ele se modifica no tempo e de acordo com a recepção (mito do significado do texto original); o tradutor não é um robô subalterno nem um gênio cosmopolita. A tradução é tanto uma arte quanto uma técnica (mito do tradutor); não existe uma tradução perfeita e 
correta, já que são possíveis muitas traduções para o mesmo texto (mito da tradução correta) (WEININGER, 2012).

Sobre a manutenção dos efeitos sonoros e rítmicos do poema no texto de chegada, o autor discorre:

\begin{abstract}
Em praticamente todos os textos poéticos, mesmo quando não há rima, incidem efeitos sonoros como assonâncias, repetição ou alternância de determinadas vogais e consoantes, sequência ou alternância de palavras curtas ou longas, com determinada acentuação, mesmo onde não há uma métrica fixa. Esses elementos, ao mesmo tempo, reforçam o conteúdo e o status do texto literário do poema. A análise da distribuição desses efeitos em cada texto antes de sua tradução permite regular a sua incidência no texto traduzido. Há momentos nos quais a forma e a sonoridade são mais importantes que o aspecto semântico. (WEININGER, 2012, p. 2010)
\end{abstract}

Esta ideia é também defendida por Laranjeira, para quem os textos de partida e de chegada devem manter uma relação semelhante a nível de significantes e não apenas lançar mão do assunto do original e adicionar-lhe a forma. Para traduzir o poema é necessário trabalhar a língua alvo:

\begin{abstract}
A poeticidade do texto reside numa relação geradora de sentidos. Traduzir o poema é trabalhar a língua de chegada para se obter uma relação semelhante a nível de significantes que acarretará uma significância correlata à do poema original. [...] [Um texto] não pode lançar mão de um assunto - um fundo - e poetizá-lo simplesmente acrescentando-lhe apêndices formais como métrica, rima etc. (LARANJEIRA, 2003, p. 29-30)
\end{abstract}

A depender do autor, época e línguas envolvidas na tradução, estas reflexões mudam. Para os tradutores romanos, por exemplo, não lhes era exigido “'dar a conhecer' nem a forma nem o conteúdo per se, e consequentemente não tinham de se sujeitar à estrutura do original" (BASSNETT, 2003, p. 83).

Com relação às línguas envolvidas - ponto significativo para o presente trabalho, já que se trata de duas línguas de modalidades e suportes de registro bastante distintos Laranjeira (2003, p. 101) afirma que quando duas línguas-culturas não possuem uma base gráfica comum, haverá dificuldades de tradutibilidade quanto à visilegibilidade. Por visilegibilidade, o autor compreende uma "[...] pré-leitura visual, baseada na distribuição espacial da massa textual, gráfica, do poema. [...] Antes de ler o poema, o leitor vê o poema e esta visão já condiciona as leituras que se darão posteriormente". A visilegibilidade de um poema em língua de sinais ocorre em um suporte visual (vídeo), o que implica uma grande mudança para que seja possível o poema chegar ao formato escrito de uma língua oral. 
Haverá sem dúvidas problemas de tradutibilidade quanto à visilegibilidade quando as línguas-culturas em contato na tradução não possuírem uma base gráfica comum, um denominador comum para a transposição visual do texto. Refiro-me, por exemplo, a tradução de um poema cujo original esteja vazado em escrita ideográfica (chinês, japonês) para outra língua-cultura que tenha escrita de base fonética (alfabetos romano, grego, eslavo). A homogeneidade espacial-visual só poderá ser mantida por meio de artifícios, ou terá de ser simplesmente abandonada, ficando a transposição da significância por conta apenas de outros elementos" (LARANJEIRA, 2003, p. 104)

Como exemplo de tradução de um poema de uma língua de sinais para a uma língua oral, temos a tradução comentada do poema "The Bridge", de Clayton Valli, produzido originalmente em Língua Americana de Sinais (ASL) e traduzido para a Língua Inglesa por Eddy (2002). Algumas questões colocadas sobre esse processo, a fim de obter uma tradução estrangeirizadora seriam refletir sobre o tema do poema, o seu significado, o agente, o local e o momento em que aconteceu a ação do poema, como o tamanho e a quebra de linhas são determinados, como se pode manter o senso de perspectiva do poema no original, como determinar a pontuação, o que existe na cultura original que está inscrito na linguagem deste poema e como ela será apresentada na língua de chegada. A intenção é "não domesticar o texto para fazê-lo mais palatável aos leitores de Inglês" (EDDY, 2002, tradução nossa). O poema "The Bridge", além de combinar vários elementos gramaticais, performativos, cria uma qualidade cinematográfica, uma qualidade que, segundo a autora, a tradução deve reter. E ainda, citando Yip (1993), Eddy afirma que uma técnica de tradução mais estrangeirizadora retém o contexto cultural e a sintaxe única da língua de partida. Assim, uma escolha estrangeirizadora permite que o leitor se aproxime mais das características particulares da língua fonte.

Steiner (2005, p. 287) coloca que estrangeirizar pode causar estranhamento e domesticar tornar o texto familiar:

Deveria uma boa tradução amoldar sua língua em direção daquela do original, criando assim uma aura deliberada de estranhamento, de opacidade periférica? $\mathrm{Ou}$ deveria naturalizar o caráter da importação linguística de modo a torná-la familiar na língua do tradutor e de seus leitores?

Sobre esta questão de estrangeirização ou domesticação, Venuti (1998, tradução nossa) comenta que poetas latinos como Horácio e Propércio traduziram textos gregos para o Latim domesticando-os e, como resultado, deletaram os marcadores culturais, incluíram 
alusões à cultura romana e por fim, substituíram o nome do poeta grego pelos seus, como se o texto tivesse sido escrito originalmente em Latim.

Já a estrangeirização implica uma pressão nos valores da cultura de chegada, fazendo chegar ao leitor as diferenças linguísticas e culturais presentes no texto estrangeiro:

Desde suas origens na tradição germânica, a tradução estrangeirizadora tem significado uma aproximação do texto estrangeiro, um literalismo que resulta na importação das formas da cultura estrangeira e desenvolvimento de dialetos e discursos heterogêneos (VENUTI, 1998, tradução nossa)

Isto pode ser sintetizado na colocação de Schleiermacher (2010, p. 57), quando afirma que "Ou bem o tradutor deixa o escritor o mais tranquilo possível e faz com que o leitor vá ao seu encontro, ou bem deixa o mais tranquilo possível o leitor e faz com que o escritor vá ao seu encontro".

Meschonnic (1973 apud OUSTINOFF, 2011, p. 64) elimina esta distinção pró-fonte e pró-alvo, afirmando que a tradução implica um descentramento, ou seja, não é definida como transporte de uma língua a outra e nem do leitor.

Uma vez que a tradução do presente trabalho é feita a partir de duas línguas usadas no solo do mesmo país, ainda que possuam características tão distintas, estrangeirizar significaria optar por apresentar aos leitores da língua de chegada - os brasileiros, ouvintes, falantes do Português - aspectos do poema sinalizado, bem específicos da poesia em língua de sinais, como a qualidade cinematográfica, citada por Eddy. Ao domesticar o texto de partida, ou seja, fazer com ele tenha aderência aos cânones literários domésticos, segundo Venuti (1998), se perderia esta propriedade e tantas outras, que serão colocadas na próxima sessão.

\section{Comentários sobre a tradução do poema "Voo sobre Rio"}

O processo de tradução iniciou com a observação detalhada do vídeo por meio do software de análises linguísticas Elan, que permite desacelerar o vídeo, criar trilhas de análise, capturar imagens. No Elan, foi criada, dentre outras, uma trilha para as glosas, que nomeiam em Português os sinais manuais em Libras e são convencionalmente padronizadas com caixa alta na literatura escrita sobre língua de sinais. Já os sinais não-manuais, que envolvem as expressões corporais e faciais, receberam caixa alta e colchetes na mesma trilha, para diferenciar dos sinais manuais. As glosas auxiliam na tradução para a Língua Portuguesa e 
permitem verificar as repetições e simetria entre os sinais. As glosas e tradução estão no anexo, no final deste trabalho.

Em uma segunda etapa, foi feita uma primeira tradução utilizando as glosas, porém observando também as pausas do poema, na tentativa de lançar hipóteses sobre a divisão do poema em versos e estrofes. Nesta fase, o processo ainda não levou em conta o ritmo, a rima e a simetria.

Para finalizar, foram analisadas atentamente as repetições, rimas e o ritmo global do poema, bem como as características cinematográficas que guiaram as escolhas tradutórias para a versão final. Neste sentido, Bauman (2006) compara a gramática da Libras ao cinema, com relação às suas propriedades básicas: câmera, sequência e edição. O sinalizador é como uma câmera, que produz imagens de diferentes ângulos; a câmera pode capturar, ainda, uma enorme variedade de sequências. Em uma sequência, muitas composições, movimentos e perspectivas podem ocorrer, bem como a sequência possuir variabilidade na velocidade. Neste poema, especificamente, a poetisa utiliza-se da mudança de perspectivas em dois trechos, em que as dimensões da mesma imagem se aproximam ou se afastam. Isto porque ele traz como tema o encontro de um casal de pássaros surdos no Rio de Janeiro e uma das aves sobrevoa a cidade, apresentando sua paisagem e pontos turísticos.

Desta forma, faz-se necessário detalhar alguns elementos presentes no poema original e, com este fim, foram selecionadas algumas imagens para ilustrar passagens e fazer comentários sobre a tradução.

\subsection{Repetições e simetria}

Ao longo do poema, foram encontradas diversas repetições, como nos sinais PÁSSARO-VOAR-GRANDE e PÁSSARO-VOAR-PEQUENO (figura 1). Esses sinais funcionam como conectores entre as diferentes partes do poema. Outros sinais são repetidos para criar simetria temporal/espacial, como os sinais da primeira e quarta parte do poema. Todos os sinais da primeira parte são repetidos no fim, porém com uma leve alteração de movimento, que é invertido, alteração dos sinais não-manuais etc. A repetição de sinais, além de criar simetria temporal/espacial, contribui para a coesão interna ao poema. A inversão da sequência de sinais e alterações também foram levadas em conta no texto-alvo. 


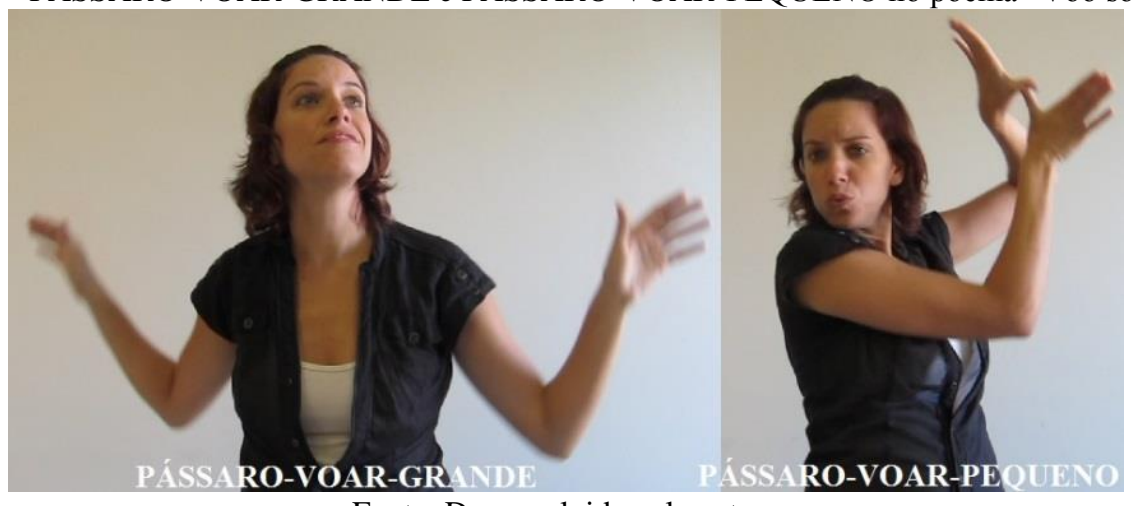

Fonte: Desenvolvida pela autora

Outro tipo de simetria presente é a simetria ou assimetria bilateral, ou seja, quando a forma (configuração de mão) que as mãos assumem são espelhadas (simetria) ou não espelhadas (assimetria). Por não haver um paralelo semelhante para este fenômeno na escrita, é um recurso que traz dificuldades ao se tentar transpor para o texto de chegada.

No texto de chegada, foram mantidas as repetições, com algumas alterações no vocabulário, a cada repetição, para que se ganhasse em poesia ou em rima interna. Os sinais da figura 1, por exemplo, representam duas dimensões do voo do pássaro (a poetisa incorporando o pássaro e logo após, o pássaro visto de uma perspectiva mais aberta, em que apenas a mão representa o pássaro voando no espaço). Estes dois sinais foram traduzidos ora como "O corpaço da ave voa/ Voa no espaço ao longe", ou "Voa a ave corpórea/ Voa ao longe" e ainda "Voa ao longe/Voa a ave corcovada", no final do poema, quando se faz referência ao Corcovado. De uma só vez, o neologismo "corcovada" remete às palavras "corpórea", "corpaço" e "curvada", fazendo referência à curva do corpo da ave sobrevoando a paisagem.

Como pode ser visto por meio das glosas presentes no anexo deste trabalho, os sinais de início e fim se repetem (I e IV partes). Um trecho repetido, por exemplo, é PLANETATERRA-PEQUENO, PLANETA-TERRA-MÉDIO, PLANETA-TERRA-GRANDE (figura 2), sinais que abrem e fecham o poema, de forma invertida. 
Figura 2: Repetição dos sinais no início e fim do poema

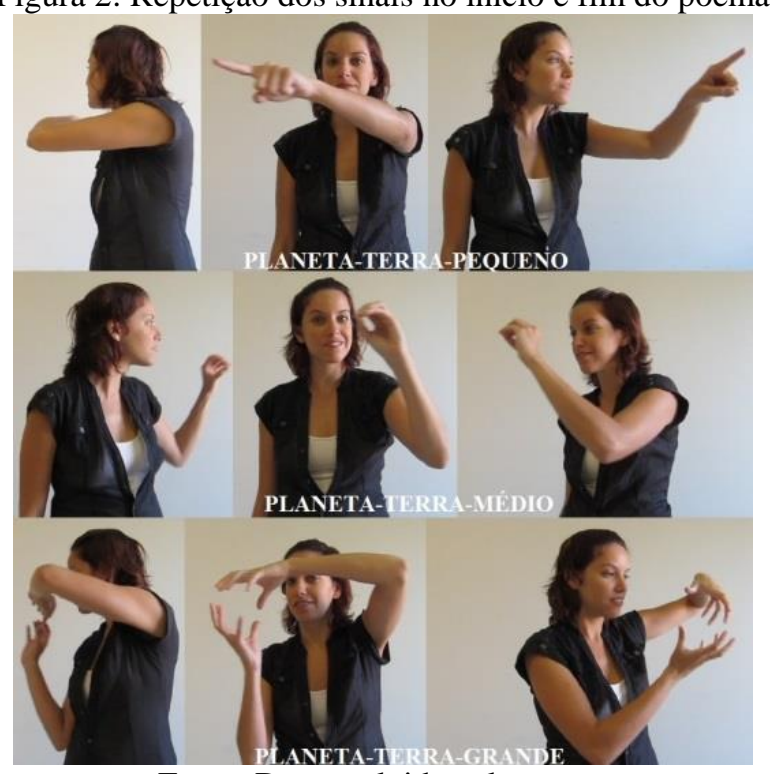

Fonte: Desenvolvida pela autora

Estes sinais mostram as três dimensões referidas anteriormente. Na ponta do dedo da poetisa, o planeta terra é minúsculo e distante; quando polegar e demais dedos se juntam em letra "o" ("grávidos no espaço"), já está mais próximo; por fim, quando o efeito de aproximação da câmera chega ao seu máximo nível, o planeta terra é grande e próximo e a configuração das mãos lembra o embalar de um ser frágil. Assim, no início do poema, estes três sinais foram traduzidos como

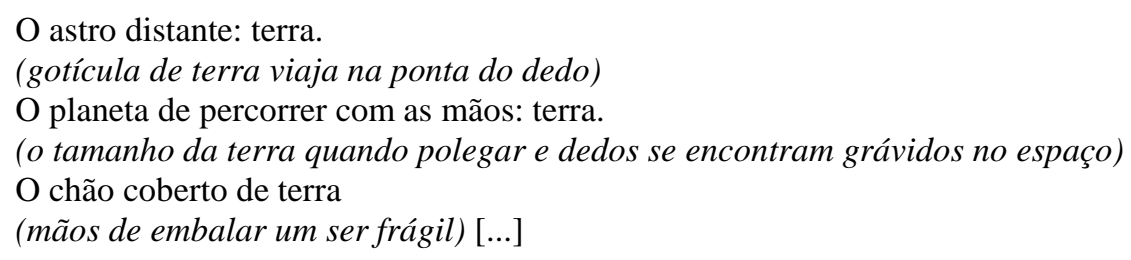

A descrição da imagem, em itálico, junto com o significado de cada sinal, auxilia o leitor a compreender e se aproximar do universo visual que a poetisa surda cria. Ao final do poema, os mesmos sinais são apresentados de forma invertida: PLANETA-TERRAGRANDE, PLANETA-TERRA-MÉDIO, PLANETA-TERRA-PEQUENO, acompanhando uma tradução também invertida, com algumas mudanças e inclusões que permitiram criar mais sentido no texto de chegada:

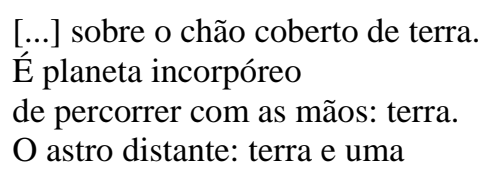

[Via-Láctea pra correr. [...] 


\subsection{Pausas}

Em língua de sinais, há um recurso denominado boia, ou seja, quando um sinal é suspenso com uma mão, enquanto com a outra se produz outro sinal. As boias são localizadas em algumas passagens, porém destacam-se nos trechos II e III. Este é um tipo de pausa na sinalização (de uma das mãos), que permite estabelecer os versos do poema. Nos trechos II e III, ocorre um diálogo entre os dois pássaros: a mão direita sempre representa o pássaro-fêmea e a mão esquerda o pássaro-macho.

\section{6}

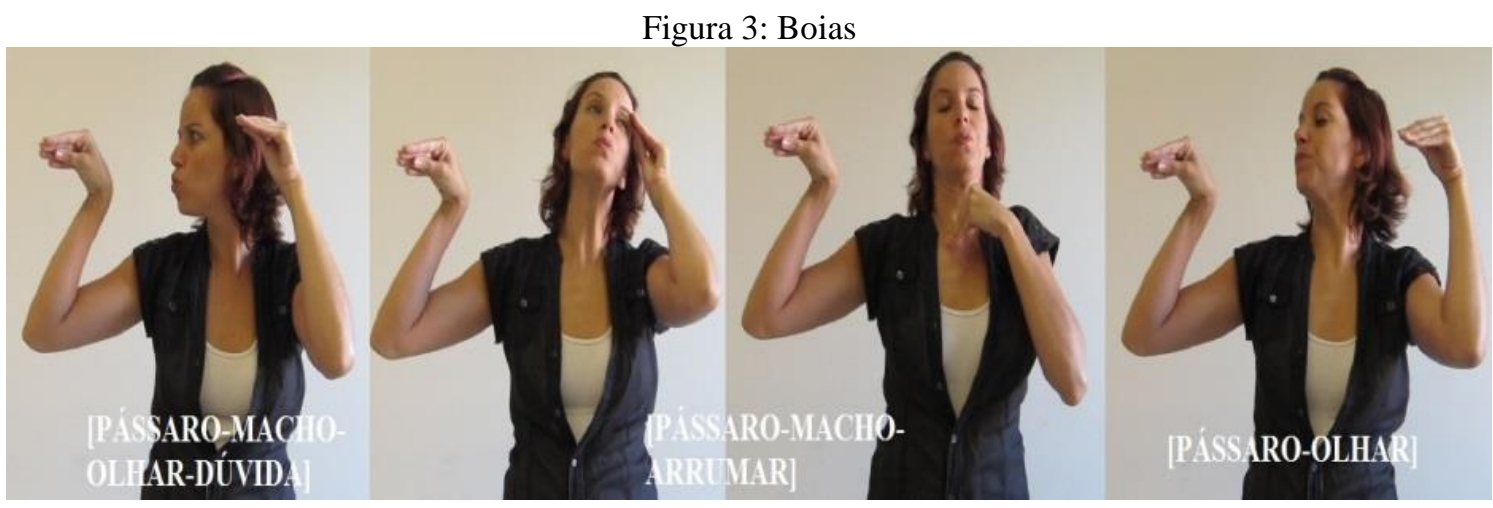

Fonte: Desenvolvida pela autora

Uma mão é suspensa, sem movimento, representando um dos pássaros que é o receptor da mensagem, enquanto a outra representa o pássaro produtor da mensagem, que realiza uma ação ou fala por meio do movimento e dos sinais não-manuais. É interessante, ainda, notar neste trecho que todos os sinais foram produzidos com a mesma configuração de mão que assume a forma, ao mesmo tempo, da cabeça e da asa das aves.

Traz-se aqui, então, um trecho do texto de chegada, em Português, para mostrar como esta dualidade entre o feminino e o masculino foi representada graficamente:

[...] O de corpaço busca.

A de corpóreo sorri, se enfeita.

Ela espia, gira o corpo de vergonha.

Ele não compreende.

Põe-se esbelto, ele dirige a vista e investe.

Ela não nota, não se vira.

Ele fala no dorso; ela não vira as costas. [...]

Além das boias, foi encontrada uma pausa significativa (14 frames) no sinal CRISTOREDENTOR-GRANDE, ilustrada na passagem da figura 4, que foi representada, na tradução, pelo fim de uma estrofe: 
Sobrevoa o Corcovado, em envergadura

(sobre a pedra, plantado, um homem de asas de cimento) como o Redentor em cruz.

(os olhos do corpo de pena se aproximam do corpo de pedra)

Cristo de braços abertos

sobre a Guanabara assiste:

(o poeta corpóreo, a redenção)

Figura 4: CRISTO-REDENTOR em três dimensões com pausa, ao final

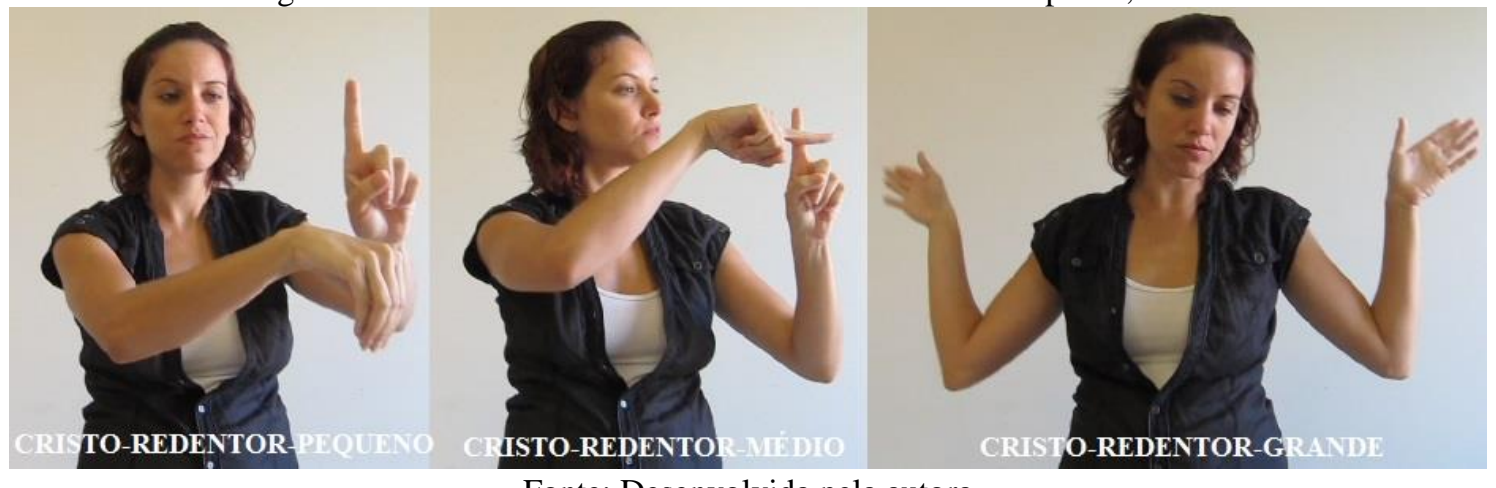

Fonte: Desenvolvida pela autora

Esta passagem também apresenta as três dimensões visuais referidas anteriormente, em que o Cristo Redentor é visto de um plano mais aberto e, portanto, mais distante (CRISTO-REDENTOR-PEQUENO), até chegar a um plano fechado e mais próximo (CRISTO-REDENTOR-GRANDE). Na primeira dimensão, nota-se que a mão esquerda da poetisa representa o Cristo e a mão direita a pedra (Corcovado); na segunda, uma cruz representa o corpo e os braços do Redentor; na terceira, o próprio corpo da poetisa incorpora o Cristo. Estas dimensões são detalhadas no texto traduzido, como pode ser visto acima.

\subsection{Rimas}

A rima presente na poesia em língua de sinais ocorre pela repetição dos fonemas presentes nos sinais, que podem ser configuração de mão, locação, movimento, orientação da palma e também podem ser rimas dos sinais não-manuais.

Em "Voo sobre Rio", exemplificamos uma rima de configuração de mão presente no poema, em que os sinais PÁSSARO-VOAR-PEQUENO e CRISTO-REDENTOR-GRANDE (figura 5) se unem pela mesma forma das mãos. 
Figura 5: Rima de configuração de mão

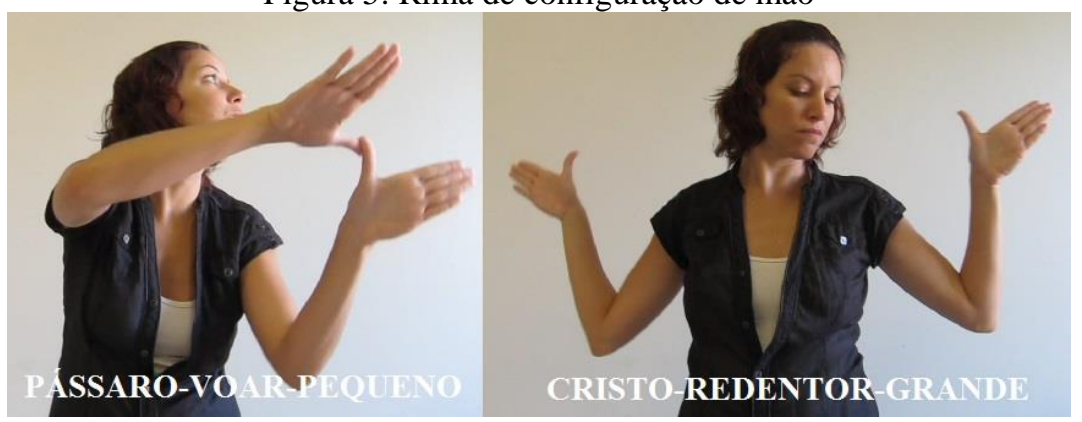

Fonte: Desenvolvida pela autora

Esta rima, na tradução, não foi resolvida por uma rima similar, mas por uma repetição da palavra "voa" e criação de uma metáfora entre as asas abertas da ave e os braços abertos do Cristo Redentor: "Voa ao longe/ Voa de asas abertas".

As repetições dos sinais, rimas, simetria, pausas contribuem, juntas, para o ritmo global do poema. O ritmo na poesia em língua de sinais é definido a partir da recorrência de elementos escolhidos pelo poeta, indicando um padrão de regularidade. Estas características da poesia em língua de sinais, assim como seu forte sentido visual, devem estar presentes no texto de chegada, sob pena de perder aspectos próprios do universo da cultura de partida, a cultura surda.

\section{Considerações finais}

A tarefa de traduzir um poema em vídeo, essencialmente visual, que tem um suporte de registro diferente do comum - a página impressa - para um formato escrito, não é simples. Implica pensar sobre questões que ainda não estão fechadas na discussão sobre poesia sinalizada, como os conceitos de verso, estrofe, rima, ritmo para trazê-las ao texto de chegada.

Não seria o caso de se falar em intraduzibilidade, pois, como já foi visto, ela estaria ligada às questões dos mitos de equivalência. Porém, ao se pretender manter algumas características do poema original, há que se enfrentar um desafio que passa, de início, por questões formais, de apresentação do texto. $\mathrm{O}$ vocabulário também não possui o valor da literalidade, já que não se pode simplesmente traduzir um sinal por uma palavra, uma vez que não há esta correspondência exata entre as línguas de sinais e as línguas orais. A equivalência e a tradução literal, desta forma, não encontram lugar ideal na tradução entre línguas de modalidades diferentes.

Assim, pode-se dizer que o tradutor possui mais liberdade para produzir um novo texto a partir das características formais e linguísticas do original, mantendo ou criando novos significados no texto de chegada. Por se tratar de um poema, no entanto, em que a estética e a 
forma são por vezes mais importantes que o conteúdo, há que se tentar trazer ao texto-alvo alguns pontos tomados da observação criteriosa do texto-fonte.

As abordagens teóricas trazidas a este trabalho possibilitaram ter diferentes visões sobre o processo tradutório, a partir de questões como (in) traduzibilidade, tradução domesticadora e estrangeirizadora e os mitos da tradução, que guiaram as escolhas feitas no momento da tradução, bem como pesquisas das línguas de sinais que apresentam paralelos entre o cinema e a literatura surda.

Por fim, a traduzibilidade da poesia entre línguas de sinais e línguas orais é, ainda, um assunto que está em aberto e que demanda muitas pesquisas para que a área possa ser desenvolvida e mais contribuições e desafios sejam colocados aos estudos das línguas de sinais.

\section{REFERÊNCIAS BIBLIOGRÁFICAS}

BASSNETT, Susan. História da tradução literária. In: Estudos da Tradução: Fundamentos de uma disciplina. Tradução de Vivina de Campos Figueiredo. Lisboa: Fundação Calouste Gulbenkian, 2003. p. 75-124

BAUMAN, H-Dirksen L. Getting-out of Line: Toward a Visual and Cinematic Poetics of ASL. In: BAUMAN, H-Dirksen L. NELSON, Jennifer. L.; ROSE, Heidi M. Signing the Body Poetic: Essays on American Sign Language Literature. 1. ed. Los Angeles: UC PRESS, 2006, cap. 5, p. 95-117.

EDDY, Shauna Lee. Signing Identity: Rethinking U. S. Poetry, Acts of Translating Sign Language, African American, and Chicano Poetry and the Language of Silence. Califórnia, 2002. 399 f. Tese. University of Southern California, California, 2002.

LARANJEIRA, Mário. Poética da tradução. Do sentido à significância. São Paulo: Editora da Universidade de São Paulo, 2003.

MESCHONNIC, Henri. Linguagem: ritmo e vida. Belo Horizonte: FALE, UFMG, 2006.

OUSTINOFF, Michael. Tradução: História, teorias e métodos. Tradução de Marcos Marcionilo. São Paulo: Parábola Editorial, 2011. Cap. 1 a 3.

SCHLEIERMACHER, Friedrich. Sobre os diferentes métodos de tradução. Tradução de Celso R. Braida. In: HEIDERMANN, Werner (Org.). Clássicos da teoria da tradução. Vol. 1, $2^{\mathrm{a}}$ ed. Florianópolis: UFSC/Núcleo de Pesquisa em Literatura e Tradução, 2010.

STEINER, George. Depois de Babel. Questões de linguagem e tradução. Tradução de Carlos Alberto Faraco. Curitiba: Editora da UFPR, 2005. 
SUTTON-SPENCE, Rachel; KANEKO, Michiko. Symmetry in Sign Language Poetry. Sign Language Studies, Washington, v. 7, n. 3, p. 234-318, 2007.

VENUTI, Lawrence. Strategies of Translation. In: BAKER, Mona (Ed.). Routledge Encyclopedia of Translation Studies. London/New York: Routledge, 1998, p. 240-244.

WEININGER, Markus Johannes. Algumas reflexões inevitáveis sobre a tradução de poesia. In: BLUME, R. F., WEININGER, M. J. (Org.) Seis décadas de poesia alemã: Do pós-guerra ao início do século XXI. Florianópolis: Editora Ufsc, 2012.

RECEBIDO EM 02/01/2015

ACEITO EM 14/01/2015 


\section{Glosas do poema "Voo sobre Rio", de Fernanda Machado}

I

PLANETA-TERRA-PEQUENO, PLANETA-TERRA-MÉDIO, PLANETATERRA-GRANDE, NUVEM

PÁSSARO-VOAR-GRANDE, PÁSSAROVOAR-PEQUENO

CRISTO-REDENTOR-PEQUENO, CRISTO-REDENTOR-MÉDIO CRISTOREDENTOR-GRANDE

PÁSSARO-VOAR-GRANDE, PÁSSAROVOAR-PEQUENO, PÃO-DE-AÇÚCAR PÁSSARO-VOAR-PEQUENO, PÁSSAROVOAR-GRANDE, PÁSSARO-VOARPEQUENO

CALÇADÃO-COPACABANA, CAMINHAR-PESSOAS

PÁSSARO-VOAR-PEQUENO, PÁSSAROVOAR-GRANDE CAMINHAR-PÁSSARO
"VOO SOBRE RIO", tradução de Marilyn Mafra Klamt e Valdemir Klamt

I

$\mathrm{O}$ astro distante: terra.

(gotícula de terra viaja na ponta do dedo) O planeta de percorrer com as mãos: terra. (o tamanho da terra quando polegar e dedos se encontram grávidos no espaço)

O chão coberto de terra (mãos de embalar um ser frágil)

e a névoa anuncia o dia.

O corpaço da ave voa.

Voa no espaço ao longe.

Sobrevoa o Corcovado, em envergadura

(sobre a pedra, plantado, um homem de asas de cimento)

como o Redentor em cruz.

(os olhos do corpo de pena se aproximam do corpo de pedra)

Cristo de braços abertos sobre a Guanabara assiste:

(o poeta corpóreo, a redenção)

O corpaço da ave voa.

Voa no espaço ao longe.

Sobrevoa o Pão de Açúcar.

Voa ao longe.

Voa a ave corpórea.

Voa ao longe.

Sobrevoa os andarilhos

no calçadão de ondas negras e brancas.

Voa ao longe.

Voa a ave corpórea.

Freia o voo:

pisa nas ondas pétreas de Copacabana. 


\begin{tabular}{|c|c|}
\hline 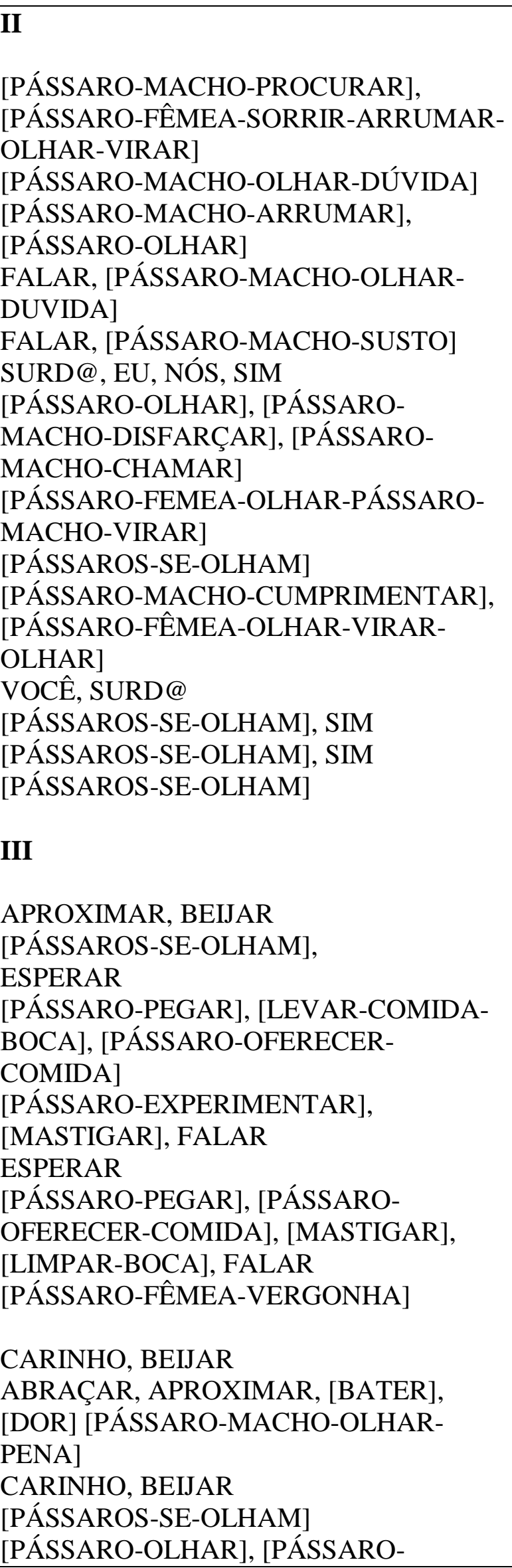 & $\begin{array}{l}\text { II } \\
\text { O de corpaço busca. } \\
\text { A de corpóreo sorri, se enfeita. } \\
\text { Ela espia, gira o corpo de vergonha. } \\
\text { Ele não compreende. } \\
\text { Põe-se esbelto, ele dirige a vista e investe. } \\
\text { Ela não nota, não se vira. } \\
\text { Ele fala no dorso; ela não vira as costas. } \\
\text { Nada sucede, apenas a dúvida. } \\
\text { Nova tentativa; nova falha. } \\
\text { O de corpaço conclui com assombro: } \\
\text { — É surda! Como eu! É surda! Como eu! } \\
\text { O toque e ela vira sem demora. } \\
\text { Os olhares são de pressa. } \\
\text { Ela gira o corpo de vergonha e sorri. } \\
\text { O corpaço e a corpóreo se entendem. } \\
\text { — Você é surdo? } \\
\text { — Sim. Sim. } \\
\text { Olhares namoram. }\end{array}$ \\
\hline
\end{tabular}




\begin{tabular}{|c|c|}
\hline $\begin{array}{l}\text { MACHO-OLHAR-DÚVIDA] [PÁSSAROS- } \\
\text { SE-OLHAM] SIM }\end{array}$ & \\
\hline IV & IV \\
\hline PÁSSARO-VOAR-PEQUENO, PÁSSARO- & Voa ao longe. \\
\hline VOAR-GRANDE, PÁSSARO-VOAR- & Voa a ave corpórea. \\
\hline PEQUENO & Voa ao longe. \\
\hline CAMINHAR-PESSOAS & Sobrevoa os andarilhos \\
\hline CALÇADÃO-COPACABANA & no calçadão de ondas negras e brancas. \\
\hline PÁSSARO-VOAR-PEQUENO, PÁSSARO- & Voa ao longe. \\
\hline VOAR-GRANDE, PÁSSARO-VOAR- & O corpaço da ave voa. \\
\hline PEQUENO & Voa no espaço ao longe. \\
\hline PÃO-DE-AÇÚCAR & Sobrevoa o Pão de Açúcar. \\
\hline PÁSSARO-VOAR-PEQUENO, PÁSSARO- & Voa no espaço ao longe. \\
\hline VOAR-GRANDE, PÁSSARO-VOAR- & O corpaço da ave voa. \\
\hline PEQUENO & Voa ao longe. \\
\hline $\begin{array}{l}\text { CRISTO-REDENTOR-GRANDE, CRISTO- } \\
\text { REDENTOR-MÉDIO CRISTO- } \\
\text { REDENTOR-PEQUENO }\end{array}$ & $\begin{array}{l}\text { Voa de asas abertas } \\
\text { como os braços do Redentor em cruz, } \\
\text { sobrevoa a cidade. } \\
\text { Sobrevoa, a ave, o Corcovado. }\end{array}$ \\
\hline $\begin{array}{l}\text { PÁSSARO-VOAR-PEQUENO, PÁSSARO- } \\
\text { VOAR-GRANDE }\end{array}$ & $\begin{array}{l}\text { Voa ao longe. } \\
\text { Voa a ave corcovada. }\end{array}$ \\
\hline $\begin{array}{l}\text { NUVEM, PLANETA-TERRA-GRANDE, } \\
\text { PLANETA-TERRA-MÉDIO, PLANETA- } \\
\text { TERRA-PEQUENO } \\
\text { TCHAU }\end{array}$ & $\begin{array}{l}\text { A névoa anuncia o dia } \\
\text { sobre o chão coberto de terra. } \\
\text { É planeta incorpóreo } \\
\text { de percorrer com as mãos: terra. } \\
\text { O astro distante: terra e uma } \\
\text { [Via-Láctea pra correr. } \\
\text { (adeus) }\end{array}$ \\
\hline
\end{tabular}

${ }^{1}$ Lattes Marilyn Mafra Klamt. Disponível em: http://lattes.cnpq.br/9023038714219436. Acesso: jan. 2015. 